Doris Götting

„Etzel“ 



\section{Doris Götting}

\section{„Etzel“}

Forscher, Abenteurer und Agent

Die Lebensgeschichte des Mongoleiforschers Hermann Consten (1878-1957)

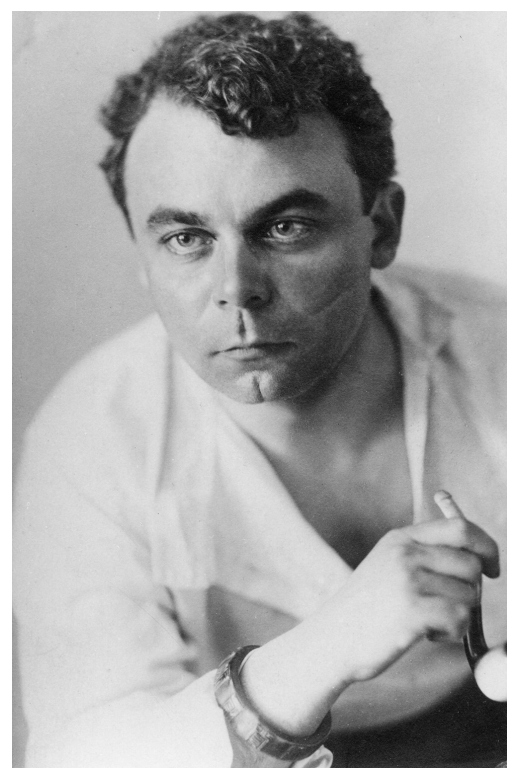




\section{Bibliografische Information der Deutschen Bibliothek}

Die Deutsche Bibliothek verzeichnet diese Publikation in der Deutschen Nationalbibliografie; detaillierte bibliografische Daten sind im Internet unter http://dnb.ddb.de abrufbar.

Titelbild: Hermann Consten im mongolischen Fürstengewand, Ölgemälde von Heinz Munz, ca. 1923

Rücken: Vignette zu Constens Roman „Der rote Lama“, unbekannter Künstler Frontispiz: Hermann Consten mit Jade-Armreif und Shag-Pfeife, um 1913.

\section{www.klaus-schwarz-verlag.com}

All rights reserved.

Alle Rechte vorbehalten. Kein Teil dieses Buches darf in irgendeiner Form (Druck, Fotokopie oder in einem anderen Verfahren) ohne schriftliche Genehmigung des Verlages reproduziert oder unter Verwendung elektronischer Systeme verarbeitet werden.

(C) 2012 by Klaus Schwarz Verlag $\mathrm{GmbH}$ Erstausgabe Gesamtherstellung: J2P Berlin Gedruckt auf chlorfrei gebleichtem Papier ISBN 978-3-87997-415-3 
Meinen mongolischen Freunden und

Anne \& Rainer Hesse gewidmet, die vor vielen fahren

mit dem Geschenk der „Weideplätze der Mongolen“ den Grundstein zu diesem Buch legten 
Ich suche immer noch nach dem Tempel des Lebens.

Ob ich ihn finde?

Hermann Consten

\begin{abstract}
Wer aber nicht auswandert aus seinem alten Menschen, der wird in keiner Steppe frei.

Hans Paasche
\end{abstract}

Man kann sicherlich sagen, dass bei denjenigen, die jemals die Welt der Geheimdienste betreten haben, die déformation professionelle nach wenigen Jahren so groß ist, dass sie nie wieder rückgängig gemacht werden kann.

fohn le Carré 